\title{
GUSTAVO DE FRAGA: FENOMENÓLOGO E METAFÍSICO
}

\author{
Pedro M. S. Alves \\ Universidade de Lisboa
}

\section{Esboço de um trajecto intelectual}

Gustavo de Fraga nasceu e morreu nos Açores, no mês de novembro dos anos de 1922 e de $2003 .{ }^{1}$ Nos oitenta e um anos que medeiam, viveu quase metade do tempo fora das ilhas numa itinerância contínua. Desde 1944, em Lisboa, onde chegou, com vinte e dois anos, para frequentar o Curso de Ciências Histórico-Filosóficas da Faculdade de Letras e onde passou pelo Serviço Militar; depois, de 1949 até 1951, em Coimbra, para conclusão da Licenciatura; de seguida, em Madrid, para preparação da Dissertação de Licenciatura sobre o objecto da Metafísica em Francisco Suárez; um pouco mais tarde, encontra-se em Bona, entre 1954 e 1957, em Paris, em 1958, e em Friburgo, entre 1959 e 1960; depois deste périplo continuado, em 1963, 1965 e 1970 fará curtas deslocações, durante a pausa de Verão na actividade docente, a Paris e aos Arquivos-Husserl de Lovaina. Entretanto, será docente do Departamento de Filosofia da Faculdade de Letras da Universidade de Coimbra, ininterruptamente, entre 1960 e 1974. Nos anos conturbados em que, na Universidade, a cátedra se converteu em tribuna e a tribuna em barricada, a sapiência e a competência filosófica de Gustavo de Fraga foram julgadas inúteis. A academia não queria ouvir falar de Husserl ou de Heidegger, de Dilthey ou de Max Scheler, de Hartmann ou de Jaspers, de Ortega y Gasset ou do Hegel da tradição metafísica, que lhe era caro. Tinha outras urgências e um outro sentido

${ }^{1}$ Mais precisamente, nasceu em 1 de novembro de 1922, na freguesia de Fajâzinha das Lajens, da ilha das Flores, e morreu em Ponta Delgada, ilha de S. Miguel, no dia 15 de novembro de 2003. 
da actualidade. O seu saber tornou-o obsoleto, as suas amizades tornaram-no suspeito. Em consequência, regressou aos Açores de seu nascimento, em cuja nova universidade, dirigida por José Enes, leccionou entre 1976 e $1988 .{ }^{2}$

As ilhas não foram, porém, apenas aqueles vinte e dois anos do amanhecer da sua vida e aqueles outros vinte e sete do seu ocaso. Há duas coisas notáveis no trajecto intelectual de Gustavo de Fraga: primeiro, o movimento - o seu percurso fora das ilhas, de Lisboa e Coimbra até Madrid, Bona, Friburgo, Paris, Lovaina, confunde-se com as etapas da sua progressiva formação como filósofo e como fenomenólogo, e é bem o sinal externo da efectiva largueza de horizontes, da vastidão de conhecimentos que caracterizam a sua personalidade intelectual; mas, em segundo lugar, há a imobilidade - Gustavo de Fraga permaneceu sempre impregnado de um certo espírito e de uma série de exigências intelectuais que ele, pelo menos por uma vez, haveria de identificar como uma certa açorianidade, bebida no berço, que o vincularia, nomeadamente, a Antero de Quental. Esse espírito determinou visivelmente a sua aprendizagem e o seu pensamento como filósofo e fenomenólogo. Poder-se-ia dizer que foi esse espírito que lhe foi dizendo, em cada momento, o que era o essencial e em que direcção deveria prosseguir. Sem ter presente essa constância, essa imobilidade de um modo de ser e de pensar que se pode educar filosoficamente, mas que não se gerou nos bancos da escola nem acordou nos seminários de Filosofia, sem consciência desta constância, dizia, a sua obra será menos inteligível.

Vejamo-lo. Gustavo de Fraga tem uma obra longa de quarenta e seis anos de escrita (de 1957 a 2003); tem também uma obra vasta, para as condições da época, com mais de uma trintena de títulos publicados; mas, sobretudo, Gustavo de Fraga tem uma obra multifacetada, tanto nos géneros como nos temas.

É tradutor. Das Meditationes de prima philosophia, de Descartes, sem as objecções e as respostas, precedidas de um longo estudo histórico-doutrinário. ${ }^{3} \mathrm{E}$ ainda de L'histoire et son enseignement, de docentes da Universidade do Quebeque, ${ }^{4}$ e de $L$ 'intention philosophique, de Joseph Vialatoux, uma obra de introdução na Filosofia, ambas com apresentações introdutórias de sua autoria. $^{5}$

2 Uma reflexão de Gustavo de Fraga, premonitória sobre os problemas e os caminhos da Universidade no mundo actual, pode ser lida em "Filosofia e Vida", Arquipélago - Revista da Universidade dos Açores. Série História e Filosofia, n. ${ }^{\circ}$ 2, VII (1985), pp. 7-29.

${ }^{3}$ René Descartes - Meditações sobre a Filosofia Primeira. Coimbra: Almedina, 1976.

${ }^{4}$ AA.VV., A História e o seu Ensino. Coimbra: Livraria Almedina, 1976.

5 Joseph Vialatoux, A Intenção Filosófica. Coimbra: Livraria Almedina, 1982 (reimpressão). 
É também ensaísta. Publicou monografias sobre Fenomenologia, com particular atenção a Husserl e a Heidegger, ${ }^{6}$ sobre a tradição da dialéctica, ${ }^{7}$ de Hegel a Marx, sobre Teoria da Cultura, ${ }^{8}$ a par de muitos artigos sobre esses temas e ainda a situação da universidade, o fenómeno da comunicação de massas, a antropologia filosófica, a obra e a personalidade de Antero de Quental e de anteristas açorianos como Ruy Galvão de Carvalho e José Bruno Carreiro, entre outros.

Mas Gustavo de Fraga é também o poeta. Poeta começou, em 1943, com Hora de Rondas, e poeta terminou, em 2003, com Rogai por Nós, Pecadores. $E$ é na poesia que se exprime de uma forma mais livre a direcção fundamental da sua personalidade como homem e intelectual. Três notas a definem: primeiro, uma certa sentimentalidade posta nas coisas miúdas da vida: um rosto, um encontro, um carinho, são, por assim dizer, consagrados pela força frágil de um afecto; depois, a devoção, profunda, de um cristianismo centrado nos mistérios da paixão e da redenção; por fim, a consciência dilacerante da finitude em busca do absoluto e da reconciliação. Numa palavra, a pulsão metafisica do Absoluto, o teísmo, vivido numa religiosidade muito "açoriana" em torno da figura do Cristo sofredor e redentor, e, por fim, a consagração festiva da vida humana nas suas formas finitas - eis as três dimensões constantes, perenes, da sua personalidade humana e intelectual.

É esta triplicidade que, em minha opinião, sendo expressa livremente na poesia, enforma e dirige todo o desenvolvimento intelectual de Gustavo de Fraga como filósofo e fenomenólogo. É também por aí que se estabelece uma relação íntima com o Antero de Quental poeta e metafísico.

De facto, Gustavo de Fraga reconhece expressamente a presença de Antero num texto de 1979, como se os irmanasse uma igual pertença às ilhas e a uma certa constelação de ideias filosóficas e metafísicas que as ilhas propiciariam: "Lembro-me de em Ponta Delgada, ainda jovem, no centenário, ter proferido uma palestra entusiástica sobre o material que as Cartas forneciam. De, em Brasília, me ter ocupado de Antero, numa conferência, durante a reunião da Sociedade Interamericana de Filosofia, no seu VIII Congresso. Agora, no regresso a Ponta Delgada e aos Açores, volto com gosto ao Antero que na inspiração me acompanhou no destino da filosofia, em particular no interesse pela filosofia alemã." Para Gustavo de Fraga, o ponto central da

${ }^{6}$ De Husserl a Heidegger. Elementos para uma Problemática da Fenomenologia. Coimbra: Universidade de Coimbra, Série de Filosofia, 1966; Sobre Heidegger: Coimbra: Livraria Almedina, 1965.

${ }^{7}$ Fenomenologia e Dialéctica. Coimbra: Universidade de Coimbra, Série de Filosofia, 1972.

${ }^{8}$ Fidelidade e Alienação. Ponta Delgada: Instituto Universitário dos Açores, 1977.

9 "Reflexão sobre Antero", Instituto Universitário dos Açores. Ponta Delgada, 1979, p. 10. 
obra do açoriano Antero está no modo como ele foi conduzido a uma alternativa metafísica fundamental. No termo de um longo comentário das concepções de von Hartmann e da sua influência sobre Antero, Fraga descreve assim essa alternativa: "Parece que se pode dizer, sem errar, que Antero oscilou entre duas concepções metafísicas, a do panteísmo, que a imanência do pensamento filosófico, segundo as categorias que aceitou, fundava, e o teísmo cristão, chegando finalmente a um esboço de síntese em que o cristianismo era fundamental para a «religião do futuro» - o seu «budismo» do Ocidente."10 A consciência aguda de que as formas finitas da vida não estão simplesmente bordejadas, mas positivamente cercadas pelo infinito, que elas como que se alçam efemeramente por sobre o indiferenciado; a consciência de que o próprio solo onde tomam forma não é uma base firme mas um magma ígneo que tudo pode destruir numa convulsão brusca; a oscilação entre dissolução do finito no infinito ou consagração do finito redimido pelo infinito - estas são, digamos, não tanto as lições da "geografia açoriana", mas de um certo modo açoriano de ser perante o mundo e a vida que Fraga reconhece em Antero e em si próprio. E Gustavo de Fraga escolheu aí onde Antero, em sua opinião, teria hesitado: escolheu pela redenção da vida finita, pelo teísmo cristão e pelo desejo de uma metafísica como filosofia do Absoluto. Foi isso que sempre se expressou na sua poesia, foi isso que, como vamos tentar mostrar, comandou também o seu trajecto como filósofo fenomenológico.

\section{Os limites da Fenomenologia}

Tendo tido relações estreitas com Karl Jaspers, que conheceu em Basileia, a ponto de ter planeado fazer do seu pensamento o tema dos estudos de doutoramento, projecto que abortou, o primeiro ponto de concentração dos estudos filosóficos de Gustavo de Fraga foi Edmund Husserl. Desde logo, esse estudo tinha começado já em Coimbra, onde Miranda Barbosa, na cadeira de Filosofia do Conhecimento, impunha o estudo parcial das Logische Untersuchungen e também de Philosophie als strenge Wissenschaft, já então traduzida para o português por Albino Beau, com um prefácio de Joaquim de Carvalho. ${ }^{11}$ Depois, o estudo continuou nos cursos de Joahnnes Thyssen, em Bona, e sobretudo no seu seminário sobre Erfahrung und Urteil, obra quase-póstuma e quase de Husserl, mas na verdade de seu assistente Ludwig Landgrebe, uma situação de fusão de autorias que, à época, era difícil de avaliar

${ }^{10}$ Idem, p. 40.

"E. Husserl, A Filosofia como Ciência Rigorosa. Coimbra: Atlântida, 1952. 
e que gerava fortes controvérsias sobre a própria coerência das posições do último Husserl. ${ }^{12}$

A primeira série de publicações de Gustavo de Fraga, a partir de 1957 e até 1966, sai desta concentração temática inicial no pensamento de Edmund Husserl e na sua Fenomenologia transcendental. Trata-se, em boa parte, de obras de aprendizagem. Escreve sobre Fenomenologia e Cartesianismo, ${ }^{13}$ onde ainda é visível, na interpretação de Descartes, a teoria de Barbosa do "mínimo inicial", escreve sobre as duas vias da redução fenomenológica, a "cartesiana" e a da Krisis, pela Psicologia, ${ }^{14}$ escreve ainda sobre a redução eidética ${ }^{15} \mathrm{e}$ sobre o tema da historicidade na Fenomenologia. ${ }^{16}$ Tudo isto são questões tradicionais e de iniciação nos fundamentos da Fenomenologia. Este trajecto adentro do pensamento de Husserl era, à época, indissociável da confrontação com a obra, ainda em desenvolvimento, de Martin Heidegger. Na verdade, duas gerações de fenomenólogos delapidaram as suas energias nesse debate estéril que quase transformou a Fenomenologia numa escolástica da análise textual em vez de numa escola viva de pesquisa sempre renovada. Eis a razão por que, no momento em que este primeiro ciclo de estudos sobre a Fenomenologia husserliana chega ao seu ponto culminante, Gustavo de Fraga tem para publicar duas obras que não são já de aprendizagem, mas, por assim dizer, frutos maduros em que, para lá do domínio das tecnicidades, se exprime toda uma interpretação global da Fenomenologia. São elas um curto ensaio sobre Heidegger ${ }^{17}$ e uma longa monografia intitulada precisamente De Husserl a Heidegger. É a sua dissertação de doutoramento, de $1966 .^{18}$

Três coisas são dignas de nota. A primeira é que estes doze anos de estudo e de publicação são a época mais produtiva de Gustavo de Fraga no que diz respeito aos estudos fenomenológicos. A segunda é que, com este ciclo

12 O papel decisivo de Ludwig Landgrebe na composição dessa obra é, hoje, fácil de avaliar devido à publicação dos manuscritos de Husserl sobre os quais trabalhou. Esses manuscritos estão hoje editados sob os títulos de Analysen zur passiven Synthesis e de Aktive Synthesen: Aus der Vorlesung "Transzendentale Logik" 1920/21, nos volumes XI e XXXI da colecção Husserliana, respectivamente.

13 "Fenomenologia e Cartesianismo". Lisboa: Edições da Revista Filosofia, 1957.

14 "As duas Vias da Redução Fenomenológica". Lisboa: Edições da Revista Filosofia, 1957.

15 “A redução Eidética na Filosofia de Husserl". Lisboa: Edições da Revista Filosofia, 1958.

16 "Ideia e Desenvolvimento da Filosofia de Husserl", em Perspectivas da Fenomenologia de Husserl. Coimbra: Universidade de Coimbra, 1965.

17 Sobre Heidegger. Coimbra: Livraria Almedina, 1965. Trata-se de uma obra de umas breves 59 páginas onde, curiosamente, a última parte discute, de uma maneira ingenuamente benevolente, não só o compromisso de Heidegger com o Nazismo, mas também o do Catolicismo alemão, de que Heidegger começou justamente por ser um dos expoentes.

18 De Husserl a Heidegger. Elementos para uma Problemática da Fenomenologia. Coimbra: Universidade de Coimbra, Série de Filosofia, 1966, 260 pp. 
de estudos e de publicações, Gustavo de Fraga passou a fazer parte, em Portugal, de um grupo muito restrito de conhecedores especializados da Fenomenologia, se não tivermos em conta a presença anterior da Fenomenologia em filósofos do Direito como Cabral de Moncada. Poucos anos antes de Gustavo de Fraga, já Júlio Fragata, de Braga, e Alexandre Morujão, de Coimbra, tinham começado a escrever e a ensinar sobre Fenomenologia. Pouco depois, surgirão Abranches de Soveral, do Porto, e Maria Manuela Saraiva, que trabalhou em Paris e mais tarde na Universidade de Lisboa. Esse grupo de cinco académicos constitui o primeiro núcleo de pensadores de inspiração verdadeiramente fenomenológica em Portugal. Entre todos eles, em minha opinião, a personalidade de Gustavo de Fraga agiganta-se pela força, pela profundidade e pela complexidade da sua leitura da Fenomenologia.

E essa é precisamente a terceira observação que importa fazer: para Gustavo de Fraga, a Fenomenologia transcendental de Husserl, a analítica existencial de Heidegger são, ambas, um momento de decepção filosófica, e o caminho de Husserl a Heidegger, que boa parte do escol universitário europeu discutia, aparece aos olhos de Gustavo de Fraga como uma via ínvia, ou seja, um não-caminho. Não porque não haja aí um trajecto possível, mas porque, para ele, esse trajecto não leva ao essencial.

A insatisfação de Gustavo de Fraga com a Fenomenologia transcendental de Husserl manifesta-se em múltiplos sinais ao longo das suas obras de aprendizagem até se exprimir de um modo plenamente desenvolvido no seu estudo monográfico final.

Há, desde logo, o significado da redução fenomenológica. Interpretada como "superação da filosofia céptica", ela é, por isso, aproximada do projecto cartesiano, ao mesmo tempo que aprofundaria e superaria o sentido cartesiano do cogito. Fraga não deixa de lançar um olhar ao mesmo tempo admirativo e suspeito sobre a epoche fenomenológica. Admira-lhe a radicalidade, mas desconfia cada vez mais seriamente do resultado que ela trará consigo. Um trecho do seu primeiro escrito fenomenológico dá já conta desta ambivalência: "[...] Perco o mundo [da natureza,] da sociabilidade e da cultura, que passam a ser «statt seinde nur seins-phänomen». É esta operação que Husserl denomina «epoché», «Aussergeltungsetzen», «Inhibieren», «Ausserspielsetzen», «Einklammern» e que nos reduz à subjectividade transcendental, à vida pura da consciência e ao universo dos fenómenos". ${ }^{19}$ A questão para Fraga será, cada vez mais, a de saber se o mundo que perco pela redução é o mundo que obtenho como fenómeno transcendental reduzido na vida da consciência pura.

19 "Fenomenologia e Cartesianismo". Lisboa: Edições da Revista Filosofia, 1957, p. 6. 
Algo se perdeu na passagem? Nomeadamente, o sentido primeiro e fundamental da própria realidade?

Esse escrúpulo estende-se ao tema husserliano da constituição do ser e do sentido na vida subjectiva, conceito que é o tema fundamental da Fenomenologia husserliana. Uma vez mais, a ambivalência de Fraga é total. Não deixa de ser sensível à própria grandeza filosófica da ideia de uma explicação integral do sentido e da validade objectivas a partir de um autodesenvolvimento da subjectividade transcendental, pois "constituição" não é apenas a correlação noética-noemática, que Husserl desenvolvera nas Ideen, de 1913, mas, como Fraga bem sabe, é também, num estrato mais profundo, teoria da génese de todo o ser e o sentido a partir da vida subjectiva. É esta radicalidade da teoria fenomenológica da subjectividade, muito para além da ideia limitada da subjectividade no cartesianismo, que Fraga admira: "Husserl pretende demonstrar que o ponto de vista fenomenológico [...], com a epoché, tem uma missão a cumprir - missão que se pode mesmo comprar com uma verdadeira transformação religiosa, isto é, a filosofia como ciência rigorosa acaba com uma afirmação de fé e de carácter profético na maior transformação existencial de que será veículo". ${ }^{20}$ Mas é também aqui que começa a divergência fundamental: "Por aqui se infere da situação da fenomenologia, que pretende explicar a constituição do ser pela subjectividade transcendental, que substitui todo o ser transcendente como explicativo da realidade do mundo - o qual também cai dentro do parênteses, preparando uma atitude adeísta, talvez mesmo radicalmente ateísta, patente em Sein und Zeit". ${ }^{21}$ Por outras palavras e indo directamente ao fulcro da questão: a subjectividade, que havia perdido o sentido da realidade na epoche, quer agora usurpar o lugar de Deus numa "criação de segunda", pomposamente chamada "constituição do sentido na vida subjectiva".

Gustavo de Fraga sabe também que esta indigência ontológica da Fenomenologia transcendental é transformada em virtude por Husserl, quando a apresenta como uma ciência pura das essências, que precede qualquer realidade dada e qualquer conhecimento na atitude natural correspondente. Por aí afirma a Fenomenologia a sua pretensão em ser ciência verdadeiramente radical, anterior a qualquer posição de um mundo que é. Mas Gustavo de Fraga, que o sabe muito bem, julga também saber que, como pura filosofia da essência, a Fenomenologia lida com "um universo que não pode ter mais realidade do que a que é concedida ao método" ${ }^{322}$ que the dá acesso. E por isso

\footnotetext{
20 "As duas Vias da Redução Fenomenológica". Lisboa: Edições da Revista Filosofia, 1957, p. 6.

21 Idem, pp. 5-6.

22 "A redução Eidética na Filosofia de Husserl". Lisboa: Edições da Revista Filosofia, 1958, p. 3.
} 
fica, na sua interpretação, a Fenomenologia diante de dois problemas que será incapaz sequer de enunciar quanto mais de resolver. Primeiro, como se passa de um sistema de simples essências para a ordem das existências - "uma existência acrescenta um mistério à essência", ${ }^{23}$ dirá. Segundo, como se dá conta do próprio sujeito fáctico que elabora essa ciência das essências ontologicamente neutra - há "um mistério da existência que descobre as essências", dirá no mesmo passo.

A sua obra madura, de 1966, haveria de encontrar o fulcro desta admiração tingida de desconfiança relativamente ao significado último do esforço filosófico de Husserl, "o maior e mais importante do século". ${ }^{25}$ Husserl entendera a sua Fenomenologia como cumprimento de uma Selbstbesinnung e de uma Selbstverantwortung do sujeito. Toda a doutrina da constituição do ser e do sentido na vida subjectiva cumpria esta intuição de que tanto o real posto como válido, como o seu sentido imanente, que tudo isso não é apenas algo para uma subjectividade, mas algo que provém da vida subjectiva enquanto processo de auto-desenvolvimento e de resposta perante si mesma. Numa palavra, o sentido da realidade é apenas aquele que construo a partir de mim próprio, ego transcendental. A apreensão do real não me põe, assim, perante outra coisa que eu mesmo. Ora é esta ideia husserliana de que o sentido último do real está determinado apenas pela responsabilidade do sujeito perante si próprio, é esta ideia de que o sujeito, na sua apreensão da realidade, não responde a e perante mais ninguém do que ele próprio, que, portanto, ele, no fundo, não propriamente apreende uma realidade, mas antes a constrói como exteriorização do sentido da sua própria vida, é esta ideia de que o sujeito detém o princípio do ser e do sentido para todo o real pensável que Gustavo de Fraga havia de rejeitar em função das suas convicções teístas e metafísicas permanentes - esse esforço de redução do ser ao ego não triunfa e a realidade é, na expressão feliz de Gustavo de Fraga, a "eterna protestante" da Filosofia de Husserl. ${ }^{26} \mathrm{E}$ é também por isso que o pensamento de Heidegger, que admira pela grandiosidade, também não exerce sobre ele qualquer fascínio. É que a via alternativa que Heidegger está trilhando continua fora e ao lado do que é, para Gustavo de Fraga, importante. Heidegger teria limitado "o ser a um finito pleno", os seus existenciais são ainda essências necessárias, de

${ }^{23}$ Idem, p. 12.

24 Ibidem.

25 "Fenomenologia e Cartesianismo". Lisboa: Edições da Revista Filosofia, 1957, p. 3.

26 "É evidente que há, em Husserl, elementos mal reduzidos ou impossiveis de reduzir, os eternos «protestantes» da sua filosofia, presentes afinal em todas as tentativas de violentar a realidade". "Ideia e Desenvolvimento da Filosofia de Husserl", em Perspectivas da Fenomenologia de Husserl. Coimbra: Universidade de Coimbra, 1965, p. 11. 
modo que a opção entre Husserl e Heidegger será a opção entre "dois essencialismos diferentes". Assim, "a ontologia de Heidegger agrava até à "incoerência", estendo-as até à hermenêutica, e, depois, à questão final do ser, as limitações da investigação fenomenológica". ${ }^{27}$ Se a volta para o Ser e a existência permitiria sonhar com uma metafísica e uma "filosofia teológica", o que acontece com Heidegger, pior ainda que com Husserl, é que ele sustenta "que a filosofia nem sequer pode pôr o problema de Deus, porque não tem modo de aceder a ele"28 a partir de uma existência pensada como finitude originária e que apenas repete numa outra clave o subjectivismo que surgira já na versão husserliana da Fenomenologia.

\section{Fenomenologia e Metafísica}

Não admira que Gustavo de Fraga feche o seu trabalho de 1966 com a questão de saber se "para além de Husserl e de Heidegger, ou mesmo com Husserl e Heidegger, não se encontram possibilidades malogradas de desenvolvimento, livres dos paradoxos do idealismo e da opacidade de um regresso impossível a partir da própria situação". ${ }^{29}$

Essas possibilidades malogradas encontrou-as Gustavo de Fraga sobretudo em Husserl. Nas suas próprias palavras, elas caminham no sentido de passar de uma Filosofia fenomenológica a uma Metafísica do Absoluto. Sem entrar nos pormenores interpretativos, assinalemos apenas os lugares dessa passagem:

- A transição husserliana do $E u$ ao $U r$-Ich, cuja auto-interpretação radical o leva o sujeito a embater numa existência já dada (a sua própria...) e numa historicidade que ele não domina.

- A ligação, também esboçada em Husserl, entre Teleologia e Teologia, apontada a mostrar que a teleologia universal da razão, que preside à constituição do mundo segundo o princípio da Serlbstverantwortung, não tem em si o seu princípio e não o domina a não ser como "instinto transcendental", ou seja, como pulsão inconsciente.

Mas para terminar, ouçamos o próprio Gustavo de Fraga esboçar o conceito e as tarefas de uma nova Metafísica: "A Filosofia não pode constituir-se sobre uma circunscrição fenoménica do pensamento. Na sua universalidade,

27 Sobre Heidegger: Coimbra: Livraria Almedina, 1965, p. 41.

28 Idem, p. 43.

${ }^{29}$ De Husserl a Heidegger. Elementos para uma Problemática da Fenomenologia. Coimbra: Universidade de Coimbra, Série de Filosofia, 1966, p. 249. 
trata do Mundo, do Homem e de Deus. Encontrar o lugar do cogito existencial numa Filosofia que recupera o Ser e o pensamento do tempo, e se queira Metafísica, será uma tarefa aliciante que, além do mais, abre o campo a uma Fenomenologia desembaraçada do preconceito de se manter encerrada, em definitivo, nas fronteiras do conceito"..$^{30}$

Pena é que estas direcções de pensamento tenham ficado em embrião no Gustavo de Fraga filósofo e que só tenham ganho uma expressão plena no Gustavo de Fraga poeta.

\section{ABSTRACT}

Gustavo de Fraga was one of the most influential Portuguese phenomenologists. He had a deep understanding of the Husserlian as well as of the Heideggerian phenomenology. One of his major concerns was the connection between these thinkers, and the resettlement of metaphysical questions some step beyond the works of both. In so doing, Gustavo de Fraga took an original stance in the field of Phenomenology, combining conceptual and poetic experiences of thought.

30 "Subjectividade e Metafisica", Revista Portuguesa de Filosofia, 3 (1988), p. 404. 